\title{
Efficient reduction of synthetic mRNA induced immune activation by simultaneous delivery of B18R encoding $\mathrm{mRNA}$
}

\author{
Tatjana Michel ${ }^{1 \dagger}$, Sonia Golombek ${ }^{1 \dagger}$, Heidrun Steinle ${ }^{1}$, Ludmilla Hann ${ }^{1}$, Ana Velic ${ }^{2}$, Boris Macek², \\ Stefanie Krajewski ${ }^{1}$, Christian Schlensak ${ }^{1}$, Hans Peter Wendel ${ }^{1}$ and Meltem Avci-Adali ${ }^{1 *}$ (D)
}

\begin{abstract}
The application of synthetic modified messenger RNA (mRNA) is a promising approach for the treatment of a variety of diseases and vaccination. In the past few years, different modifications of synthetic mRNA were applied to render the mRNA more stable and less immunogenic. However, the repeated application of synthetic mRNA still requires the suppression of immune activation to avoid cell death and to allow a sufficient production of exogenous proteins. Thus, the addition of type I interferon (IFN) inhibiting recombinant protein B18R is often required to avoid IFN response. In this study, the ability of B18R encoding mRNA to prevent the immune response of cells to the delivered synthetic mRNA was analyzed. The co-transfection of enhanced green fluorescent protein (eGFP) mRNA transfected fibroblasts with B18R encoding mRNA over 7-days resulted in comparable cell viability and eGFP protein expression as in the cells transfected with eGFP mRNA and incubated with B18R protein. Using qRT-PCR, significantly reduced expression of interferon-stimulated gene Mx1 was detected in the cells transfected with B18R mRNA and stimulated with IFN $\beta$ compared to the cells without B18R mRNA transfection. Thereby, it was demonstrated that the co-transfection of synthetic mRNA transfected cells with B18R encoding mRNA can reduce the IFN response-related cell death and thus, improve the protein expression.
\end{abstract}

Keywords: Immune response, B18R, Modified mRNA, Type I IFN

\section{Introduction}

During the last few years, synthetic messenger RNA (mRNA) has gained great interest as a therapeutic agent. The synthetic mRNA-based therapies promise new opportunities for the treatment of different diseases by the induction of functional protein expression in desired cells [1-4]. Synthetic mRNA-based therapy has major advantages compared to retroviral gene therapy: (i) the mRNA does not need to enter the nucleus for translation [4-6], (ii) the translation of the mRNA takes place under physiological conditions in the cytosol, (iii) the desired proteins can be produced without integration

\footnotetext{
* Correspondence: meltem.avci-adali@uni-tuebingen.de

†Tatjana Michel and Sonia Golombek contributed equally to this work.

${ }^{1}$ Department of Thoracic and Cardiovascular Surgery, University Hospital

Tübingen, Tübingen, Germany

Full list of author information is available at the end of the article
}

into the genome [7, 8], and (iv) the expression of proteins by the exogenously delivered synthetic mRNAs is transient [9].

To increase the translation and stability of synthetic mRNAs, different types of modifications can be introduced during the in vitro transcription (IVT) [10, 11]. A poly-(A)-tail is attached to the 3 '-end to enhance the stability and translation of synthetic mRNA [12]. In addition, a synthetic cap analog, such as the anti-reverse cap analog (ARCA, 3'-O-Me-m7G(5')ppp(5')G RNA cap structure analog), can be used to further increase the mRNA stability and translation efficiency. In ARCA, the $3^{\prime}-\mathrm{OH}$ of the $\mathrm{m}^{7} \mathrm{G}$ moiety is substituted by a $3^{\prime}-\mathrm{O}-$-methyl group, which enables the incorporation of the cap analog in the correct orientation at the $5^{\prime}$-end during the IVT [13]. Thereby, the mRNA degradation is prevented, the translation efficiency is improved, and the immune 
activation is reduced $[14,15]$. Furthermore, the incorporation of modified nucleosides like 5-methylcytidine (m5C) and pseudouridine $(\Psi)$ during the IVT into the synthesized mRNA enhances on the one hand the expressed protein level [16-18] and biological stability [16] and on the other hand suppresses the activation of the immune system $[16,19,20]$.

However, in spite of these modifications, the exogenously delivered synthetic mRNA has still the potential to induce an immune activation in the cells. Pattern recognition receptors (PRRs), such as the Toll-like receptors (TLRs) $3,7,8[21,22]$ or the retinoic acid inducible gene I (RIG-I) [23], are able to recognize foreign RNAs inside the cells, which subsequently lead to an immune response. Thus, the recognition of exogenously delivered synthetic mRNA can lead to the activation of nuclear factor $\kappa \mathrm{B}(\mathrm{NF}-\kappa \mathrm{B})$ in the cells and result in expression of type I interferons (IFNs) and proinflammatory cytokines [21, 22, 24-27]. Interferon- $\alpha$ (IFN $\alpha)$ and interferon- $\beta$ (IFN $\beta)$ are the effector molecules that together form type I IFNs and mediate immune responses in cells. Thereby, defense mechanisms are activated, which lead to the depletion of the foreign RNA and inhibit the translation of mRNAs [28, 29].

Type I IFNs bind to the transmembrane interferon receptors on the cell surface and induce an antiviral state in the cells, which naturally inhibits the virus replication and reduces viral spread. The binding to the interferon receptor leads to the activation of cytoplasmic signal transductors and activators of transcription (STATs). Subsequently, the transcription of IFN-stimulated genes (ISGs) is induced in the nucleus. The products of these ISGs have numerous antiviral effector functions [29, 30]. One of the antiviral proteins encoded by ISGs is the interferon-induced GTP-binding Mx1 protein. The Mx1 protein is a GTPase, which is responsible for a specific antiviral response. Thereby, viral infections are inhibited by blocking viral transcription and replication [31, 32]. However, viruses also developed various strategies to escape this antiviral response. For example, the vaccinia virus encoded B18R protein functions as a soluble receptor for IFN $\alpha$ and IFN $\beta$. This protein can exist as a soluble extracellular as well as a cell surface bound protein [33] and has a high affinity for type I IFNs. Thus, the binding of the B18R protein can block the autocrine and paracrine function of type I IFNs. Furthermore, it can also bind to the cell surface of uninfected and infected cells [34], and thereby reduce the inflammatory signal.

The repeated transfection of cells with synthetic mRNA and the following induction of IFNs result in a rapid decrease of cell viability $[35,36]$. Therefore, if the delivery of synthetic mRNA is required over an extended period, such as for the reprogramming of cells into induced pluripotent stem cells (iPSCs), recombinant
B18R protein can be applied to avoid the immune activation of cells and to block the activity of type I IFNs. Thus, in previous studies, the addition of recombinant $\mathrm{B} 18 \mathrm{R}$ protein during the long-term cell reprogramming experiments with synthetic mRNAs led to an increased cell viability and a successful reprogramming of cells into iPSCs [37-39].

In this study, the effectivity of synthetic B18R mRNA co-delivery into cells along with the exogenously delivered mRNA encoding the desired protein was analyzed in order to simultaneously suppress synthetic mRNA induced immune activation in cells. The strategy of synthetic B18R mRNA delivery-based reduction of type I IFN response is presented in Fig. 1.

\section{Materials and methods}

\section{Synthesis of modified mRNA}

Amplification of plasmid inserts and adding of poly-T-tail by polymerase chain reaction (PCR)

The pcDNA 3.3 vector containing the coding sequence (CDS) of B18R (Aldevron, Fargo, North Dakota, US) or enhanced green fluorescent protein (eGFP) (Addgene, cat. no. 26822) [37] was used as template. To amplify the CDS of B18R and eGFP, the Hotstar HiFidelity Polymerase Kit (Qiagen, Hilden, Germany) was used in accordance with the manufacturer's instructions. For the PCR, $100 \mathrm{ng}$ plasmid DNA, $0.7 \mu \mathrm{M}$ of the forward primer, 5'-TTGGACCCTCGTACAGAAGCTAATACG-3' and $0.7 \mu \mathrm{M}$ of the reverse primer, $\mathrm{T}_{120}$-CTTCCTACTCAGGCTTTATTCAAAGACCA-3' (Ella Biotech, Martinsried, Germany), were used. PCR was performed using the following cycling protocol: initial activation step at $95^{\circ} \mathrm{C}$ for $5 \mathrm{~min}$, followed by 25 cycles of denaturation at $95^{\circ} \mathrm{C}$ for $45 \mathrm{~s}$, annealing at $58^{\circ} \mathrm{C}$ for $1 \mathrm{~min}$, extension at $72{ }^{\circ} \mathrm{C}$ for $1 \mathrm{~min}$, and final extension at $72{ }^{\circ} \mathrm{C}$ for $5 \mathrm{~min}$. After the DNA amplification, PCR products were purified using QIAquick PCR purification kit (Qiagen) and eluted in $2 \times 20 \mu \mathrm{l}$ nuclease-free water (Qiagen). The quality and purity of the DNA were assessed by $1 \%$ agarose gel electrophoresis.

\section{IVT}

The IVT of the DNA into mRNA was performed using MEGAscript ${ }^{\circ}$ T7 Kit (Life Technologies, Darmstadt, Germany) according to the manufacturer's instructions. Therefore, $40 \mu \mathrm{l}$ IVT reaction mixture containing 7.5 mM ATP, $1.875 \mathrm{mM}$ GTP (both from MEGAscript ${ }^{\circ}$ T7 Kit), $7.5 \mathrm{mM}$ m5C (TriLink BioTechnologies, San Diego, USA), $7.5 \mathrm{mM} \Psi$ (TriLink BioTechnologies), $2.5 \mathrm{mM}$ ARCA (New England Biolabs, Frankfurt am Main, Germany), $40 \mathrm{U}$ RiboLock RNase inhibitor (Thermo Fisher Scientific, Waltham, USA), $1.5 \mu \mathrm{g}$ PCR product, $1 \mathrm{x}$ reaction buffer and $1 \mathrm{x}$ T7 RNA polymerase enzyme mix was prepared. The mixture was incubated for $4 \mathrm{~h}$ at 


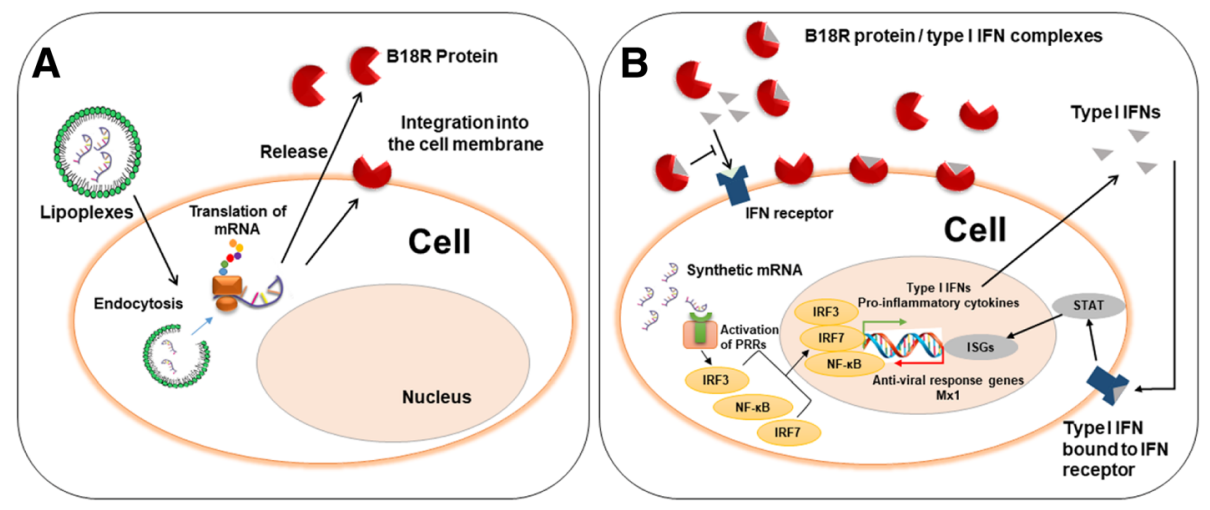

Fig. 1 Schematic representation of the synthetic B18R mRNA transfection and translation process and the inhibition of type I interferon (IFN) immune response. (a) Lipoplexes are generated by complexing the B18R encoding mRNA with Lipofectamine 2000. After the uptake of lipoplexes into the cells by endocytosis and the subsequent endosomal escape, the synthetic B18R mRNA is translated by the ribosomes into functional B18R protein. Then, B18R is released into the supernatant or integrated into the cell membrane. (b) The recognition of synthetic mRNA by pattern recognition receptors (PRRs) in the cells leads to the activation of NF-KB, IRF3, and IRF7, which results in the expression of proinflammatory cytokines, e.g. type I IFNs. The produced type I IFNs bind to the IFN receptors and induce the expression of interferon-stimulated genes (ISGs), such as Mx1. The synthesized B18R proteins can capture type I IFNs produced by mRNA transfected cells, and thereby, reduce the inflammatory reaction

$37^{\circ} \mathrm{C}$, then $1 \mu \mathrm{l}$ TURBO DNase (from MEGAscript ${ }^{\circ} \mathrm{T}$ Kit) was added to the IVT reaction mixture and incubated for $15 \mathrm{~min}$ at $37^{\circ} \mathrm{C}$ to remove the template DNA. After the incubation, mRNA was purified using RNeasy Mini Kit (Qiagen) according to the manufacturer's instructions and eluted in $2 \times 20 \mu \mathrm{l}$ nuclease-free water. Subsequently, dephosphorylation was performed with $10 \mathrm{U}$ Antarctic phosphatase (New England Biolabs) at $37^{\circ} \mathrm{C}$ for $30 \mathrm{~min}$. The mRNA was purified and eluted in $50 \mu \mathrm{l}$ nuclease-free water using RNeasy Mini Kit. The concentration was measured using ScanDrop spectrophotometer (Analytic Jena, Jena, Germany) and adjusted to $100 \mathrm{ng} / \mu \mathrm{l}$ by adding nuclease-free water. The quality and purity of the synthesized and modified mRNA were confirmed in a $1 \%$ agarose gel. The modified mRNA was stored at $-80{ }^{\circ} \mathrm{C}$ and used for transfections.

\section{Cultivation of cells}

BJ human foreskin fibroblasts (Stemgent, Cambridge, USA) were cultivated in DMEM with high glucose containing $10 \%$ fetal calf serum (FCS), 2 mM L-glutamine, $1 \%$ penicillin/streptomycin, and $30 \mathrm{mM}$ HEPES. Cell culture medium and supplements were obtained from Thermo Fisher Scientific (Waltham, USA). Cells were kept at $37{ }^{\circ} \mathrm{C}$ with $5 \% \mathrm{CO}_{2}$ and medium was changed every 3 days. Cells were passaged using trypsin/EDTA (0.04\%/0.03\%, PromoCell, Heidelberg, Germany).

Transfection of fibroblasts with synthetic modified mRNA To perform transfection of cells, $1 \times 10^{5}$ fibroblasts were seeded per well of a 6 -well plate and cultivated overnight at $37{ }^{\circ} \mathrm{C}$ and $5 \% \mathrm{CO}_{2}$. Next day, the mRNA transfection of cells was performed. For the transfection, $1 \mathrm{ml}$
Opti-MEM I reduced serum medium (Life Technologies, Darmstadt, Germany), $4 \mu \mathrm{l}$ Lipofectamine 2000 (Thermo Fisher Scientific) and $1.5 \mu \mathrm{g}$ eGFP mRNA or $1.5 \mu \mathrm{g}$ eGFP mRNA and 0.2 to $1.5 \mu \mathrm{g}$ B18R mRNA were mixed and incubated for $20 \mathrm{~min}$ at room temperature (RT) to form lipoplexes. The cells were washed with DPBS w/o $\mathrm{Ca}^{2+} / \mathrm{Mg}^{2+}$ (Thermo Fisher Scientific) and incubated with the transfection complexes for $4 \mathrm{~h}$ at $37^{\circ} \mathrm{C}$ and $5 \% \mathrm{CO}_{2}$. After the incubation, the transfection mixture was replaced by cell culture medium.

\section{Detection of B18R protein in B18R mRNA transfected fibroblasts using mass spectrometry (MS)}

Since no commercially available antibody against B18R is available, proteome analysis was performed using MS to detect the successful production of B18R in the cells after the transfection with B18R mRNA.

\section{Isolation of proteins}

Fibroblasts were transfected with $1.5 \mu \mathrm{g}$ B18R mRNA and after $24 \mathrm{~h}$, cells were rinsed with cold DPBS and lysed on ice using $200 \mu \mathrm{l}$ of Pierce ${ }^{\mathrm{TM}}$ RIPA buffer (Thermo Fisher Scientific) containing $1 \mathrm{x}$ Halt ${ }^{\mathrm{TM}}$ Protease Inhibitor Cocktail (Thermo Fisher Scientific) for $5 \mathrm{~min}$. After the sonification for $1 \mathrm{~min}$ at RT in an ultrasonic bath, cell lysates were centrifuged at $14.000 \mathrm{~g}$ for $25 \mathrm{~min}$ at $4{ }^{\circ} \mathrm{C}$. Supernatants were collected and stored at $-80^{\circ} \mathrm{C}$. Protein concentrations were determined using Pierce $^{\text {тм }}$ BCA Protein Assay kit (Thermo Fisher Scientific) and the microplate reader EON Synergy 2 BioTek instruments (Bad Friedrichshall, Germany). 


\section{SDS-PAGE and Coomassie blue staining}

From the obtained protein sample, $20 \mu \mathrm{g}$ of protein was mixed with $1 \mathrm{x}$ Laemmli sample buffer (Bio-Rad, Munich, Germany), denatured for $5 \mathrm{~min}$ at $95^{\circ} \mathrm{C}$, and separated by using $10 \%$ SDS-PAGE at $200 \mathrm{~V}$ for $25 \mathrm{~min}$. The gel was incubated in a fixation solution composed of $50 \%$ ethanol and $10 \%$ acetic acid in $\mathrm{ddH}_{2} \mathrm{O}$ for $30 \mathrm{~min}$ at RT. Then, the gel was stained with Coomassie Brilliant Blue R-250 staining solution (Bio-Rad) for $10 \mathrm{~min}$ at RT, destained in $7.5 \%$ acetic acid and $25 \%$ methanol in $\mathrm{ddH}_{2} \mathrm{O}$ for $1 \mathrm{~h}$ at $\mathrm{RT}$ and stored in $\mathrm{ddH}_{2} \mathrm{O}$ overnight. Afterwards, a single band at around $42 \mathrm{kDa}$ and additionally all bands from around 25 to $100 \mathrm{kDa}$ were cut out and used for MS analysis.

\section{Proteome analysis}

Tryptic digestion of proteins: For proteome analysis, gel pieces were digested as described previously [40].

Liquid Chromatography (LC)-MS/MS: LC-MS/MS analyses were performed on an EasyLC nano-HPLC (Proxeon Biosystems) coupled to an LTQ Orbitrap Elite (Thermo). Separations of the peptide mixtures were done on a $15 \mathrm{~cm}$ fused silica emitter of $75 \mu \mathrm{m}$ inner diameter (Proxeon Biosystems), in-house packed with reversed-phase ReproSil-Pur C18-AQ $3 \mu \mathrm{m}$ resin (Dr. Maisch $\mathrm{GmbH}$ ). Peptides were injected with solvent A $(0.5 \%$ acetic acid) at a flow rate of $500 \mathrm{nl} / \mathrm{min}$ and separated at $200 \mathrm{nl} / \mathrm{min}$. The separation was performed using a linear 75 min gradient of $5-33 \%$ solvent B (80\% ACN in $0.5 \%$ acetic acid). LTQ Orbitrap Elite was operated in the positive ion mode. Precursor ions were acquired in the mass range from $\mathrm{m} / \mathrm{z} 300$ to 2000 in the Orbitrap mass analyzer at a resolution of 120,000 followed by MS/MS spectra acquisition. The 15 most intense precursor ions from the full scan were sequentially fragmented.

MS Data Processing and Analysis: Acquired MS spectra were processed with MaxQuant software package version 1.5.2.8 [41, 42], integrated with Andromeda search engine. Database search was performed against a human database obtained from Uniprot taxonomy ID 9606, containing 93,827 protein entries and 247 commonly occurring laboratory contaminants. Additionally, we used also the viral database for vaccinia virus Uniprot taxonomy 10,245, containing 5023 protein entries. Tryp$\sin$ was fixed as the protease with a maximum missed cleavage of two. Oxidation of methionines and $\mathrm{N}$-terminal acetylation were specified as variable modifications. Initial maximum allowed mass tolerance was set to six ppm. Carbamidomethylation on cysteines was defined as a fixed modification. Re-quantify was enabled and a false discovery rate of $1 \%$ was applied at the peptide and protein level.
Quantitative real-time polymerase chain reaction (qRT-PCR) analyses of Mx1 expression to evaluate the type I IFN reaction inhibiting effect of B18R mRNA delivery

The interferon-induced GTP-binding protein Mx1 is expressed in the cells after the binding of IFNs to the IFN receptors on the cell surface [30]. To measure the type I IFN reaction inhibiting effect of B18R mRNA by production of $\mathrm{B} 18 \mathrm{R}$ protein, the $\mathrm{Mx} 1 \mathrm{mRNA}$ expression level in the B18R mRNA transfected cells was determined. Therefore, $1 \times 10^{5}$ fibroblasts were seeded per well of a 6-well plate. Next day, cells were transfected with $1.5 \mu \mathrm{g}$ B18R mRNA and incubated for $4 \mathrm{~h}$ at $37^{\circ} \mathrm{C}$ and $5 \% \mathrm{CO}_{2}$. Afterwards, the transfection mixture was replaced by cell culture medium and the cells were incubated for $24 \mathrm{~h}$ at $37^{\circ} \mathrm{C}$. Subsequently, the cells were incubated for $3 \mathrm{~h}$ at $37^{\circ} \mathrm{C}$ and $5 \% \mathrm{CO}_{2}$ with $5 \mathrm{ng} / \mathrm{ml}$ recombinant human IFN $\beta$ (PeproTech, Hamburg, Germany).

\section{Isolation of RNA and CDNA synthesis}

After stimulation with $5 \mathrm{ng} / \mathrm{ml}$ recombinant human IFN $\beta$, fibroblasts were rinsed twice with DPBS. Total RNA was extracted using the Aurum Total RNA Mini Kit (Bio-Rad) according to the manufacturer's instructions. Then, cDNA was generated from $200 \mathrm{ng}$ total RNA using iScript ${ }^{\mathrm{Tm}}$ cDNA Synthesis Kit (Bio-Rad) with following conditions: $5 \mathrm{~min}$ at $25^{\circ} \mathrm{C}, 30 \mathrm{~min}$ at $42^{\circ} \mathrm{C}$, and $5 \mathrm{~min}$ at $85^{\circ} \mathrm{C}$. The synthesized cDNA was diluted 1:10 for qRT-PCR.

\section{qRT-PCR}

The qRT-PCR was performed using iQ SYBR Green Supermix (Bio-Rad) according to the supplier's recommendations. The reactions were run in triplicates in an iCycler iQ Real-Time PCR detection system (Bio-Rad). The expression of the constitutively expressed gene glyceraldehyde 3-phosphate dehydrogenase (GAPDH) served as an internal control for the amount of RNA input. Initial cDNA denaturation was performed at $95^{\circ} \mathrm{C}$ for 3 min, followed by 40 cycles of denaturation at $95^{\circ} \mathrm{C}$ for $15 \mathrm{~s}$, annealing at $63^{\circ} \mathrm{C}$ for $30 \mathrm{~s}$, extension at $72^{\circ} \mathrm{C}$ for $10 \mathrm{~s}$. Levels of mRNA were normalized to GAPDH and the results are shown relative to control mRNA levels in samples treated with medium containing Lipofectamine 2000. The primers used for the specific amplification of transcripts were ordered from Ella Biotech (Martinsried, Germany). For the detection of $\mathrm{Mx} 1$ transcripts, the forward primer 5'-AGACAGGACCATCGGAATCT-3' and the reverse primer $5^{\prime}$-ACGT CCACAACCTTGTCTTC-3' were used, and GAPDH transcripts were detected using the forward primer 5' -TGAACCACCAACTGCTTAGC-3' and the reverse primer 5'-GGCATGGACTGTGGTCATGAG-3'. 
Co-transfection of cells simultaneously with synthetic eGFP and B18R mRNA

\section{Analysis of cell viability}

To investigate the impact of synthetic B18R mRNA co-transfection on the cell viability, $1 \times 10^{5}$ fibroblasts were seeded per well of 6-well plate. After $24 \mathrm{~h}$, daily transfection of fibroblasts with $1.5 \mu \mathrm{g}$ eGFP mRNA with or without $1.5 \mu \mathrm{g}$ B18R mRNA was performed. Furthermore, cells transfected with $1.5 \mu \mathrm{g}$ eGFP mRNA were cultivated without or with $200 \mathrm{ng} / \mathrm{ml}$ B18R protein (Stemgent, Lexington, USA). After each transfection, cells were incubated $24 \mathrm{~h}$ with the cell culture medium with or without B18R protein. Subsequently, cells were washed three times with DPBS and $300 \mu \mathrm{RPMI}$ without phenol red (Life Technologies) containing $0.5 \mu \mathrm{g} / \mathrm{ml}$ MTT (3-(4,5-dimethylthiazol-2-yl)-2,5-diphenyltetrazoliumbromide, AppliChem, Darmstadt, Germany) was added to the cells. After $4 \mathrm{~h}$ of incubation at $37^{\circ} \mathrm{C}$ and $5 \% \mathrm{CO}_{2}$, the medium was removed and the formazan products were solubilized by adding $300 \mu \mathrm{l}$ of dimethyl sulphoxide (DMSO, SERVA Electrophoresis, Heidelberg, Germany) to each well of the 6-well plate for $10 \mathrm{~min}$ at $37^{\circ} \mathrm{C}$. The absorbance was measured at $540 \mathrm{~nm}$ using a microplate reader (Mithras, Bad Wildbach, Germany).

\section{Analysis of eGFP expression}

To analyze the eGFP expression in cells after the co-transfection with eGFP and B18R encoding mRNA, fibroblasts were seeded with the density of $1 \times 10^{5}$ cells per well of the 6-well plate. The transfection complexes were formed by mixing $1.5 \mu \mathrm{g}$ of eGFP mRNA and 0.2 , 0.5 , 1 , or $1.5 \mu \mathrm{g}$ B18R mRNA with $4 \mu$ l Lipofectamine 2000 in $1 \mathrm{ml}$ Opti-MEM. After the incubation for 20 min at RT, transfection complexes were added to the cells and incubated for $4 \mathrm{~h}$ at $37^{\circ} \mathrm{C}$ and $5 \% \mathrm{CO}_{2}$. Afterwards, the transfection mixture was replaced by cell culture medium. The expression of eGFP was analyzed $24 \mathrm{~h}$ after the first transfection and $24 \mathrm{~h}$ after the second transfection using flow cytometry and fluorescence microscopy. For the flow cytometry, cells were detached, washed with DPBS and fixed in $1 \mathrm{x}$ CellFIX (BD Bioscience, Heidelberg, Germany). The flow cytometry measurements were performed using FACScan (BD Bioscience). The fluorescence microscopy was performed using Zeiss Axio Microscope (Zeiss, Oberkochen, Germany).

\section{Statistical analysis}

Data are shown as means \pm standard error of the mean (SEM). Kolmogorov-Smirnov test was used for the normality test. Normally distributed data were analyzed using one-way or two-way analysis of variance (ANOVA). Samples with non-normal distribution were analyzed using the Kruskal-Wallis test. For all statistical analysis, the software GraphPad Prism (version 6, GraphPad Software, La Jolla, USA) was used. Statistical significance was defined as $p<0.05$.

\section{Results}

Production of synthetic B18R mRNA

Using PCR, the CDS of B18R including 5'UTR, 3'UTR, and a poly-T-tail was amplified (Fig. 2). After the purification, the amplified DNA fragment was analyzed using $1 \%$ agarose gel electrophoresis. A clear band of approximately 1400 bases was detected. The subsequent IVT led to the production of the synthetic B18R mRNA with a length of about 1400 bases (Fig. 2).

\section{Proteome analysis for the detection of translated B18R protein in the cells}

Fibroblasts were transfected with $1.5 \mu \mathrm{g}$ eGFP mRNA. After $24 \mathrm{~h}$, cells were lysed, $20 \mu \mathrm{g}$ of the obtained protein was separated by SDS-PAGE, and proteome analysis was performed using LC-MS/MS. The analysis resulted in detection of 4 different peptides, which are specific for B18R protein (UniProtKB-Q9DUN2) (Table 1).

\section{Analysis of Mx1 gene expression after the transfection of cells with B18R mRNA}

To examine the ability of the delivered synthetic B18R mRNA to reduce the interferon-induced immune reaction by the production of $\mathrm{B} 18 \mathrm{R}$ protein, fibroblasts were incubated after the B18R mRNA transfection with IFN $\beta$. The expression of $M x 1$ transcripts was determined by using qRT-PCR. IFN $\beta$ stimulation of cells transfected with B18R mRNA or incubated with B18R protein resulted in a highly significant reduction of Mx1 expression, which showed the successful inhibition of IFN $\beta$ by the produced B18R protein in the cells (Fig. 3).

\section{Impact of B18R mRNA co-transfection on the translation of eGFP $m R N A$ and cell viability Expression of eGFP after the co-transfection of cells with B18R mRNA}

To analyze the influence of B18R mRNA co-transfection on eGFP protein expression, $1 \times 10^{5} \mathrm{fi}$ broblasts were transfected simultaneously with $1.5 \mu \mathrm{g}$ eGFP mRNA and $0.2,0.5,1$, or $1.5 \mu \mathrm{g}$ B18R mRNA. After $24 \mathrm{~h}$, the cells were co-transfected again with the same amount of eGFP and B18R mRNA and incubated for $24 \mathrm{~h}$. Flow cytometry analyses were performed $24 \mathrm{~h}$ after the first and the second transfection (Fig. 4). The co-transfection of cells with B18R mRNA showed no influence on eGFP expression $24 \mathrm{~h}$ after the first transfection (Fig. 4a). However, $24 \mathrm{~h}$ after the second transfection, cells co-transfected with eGFP mRNA and B18R mRNA 

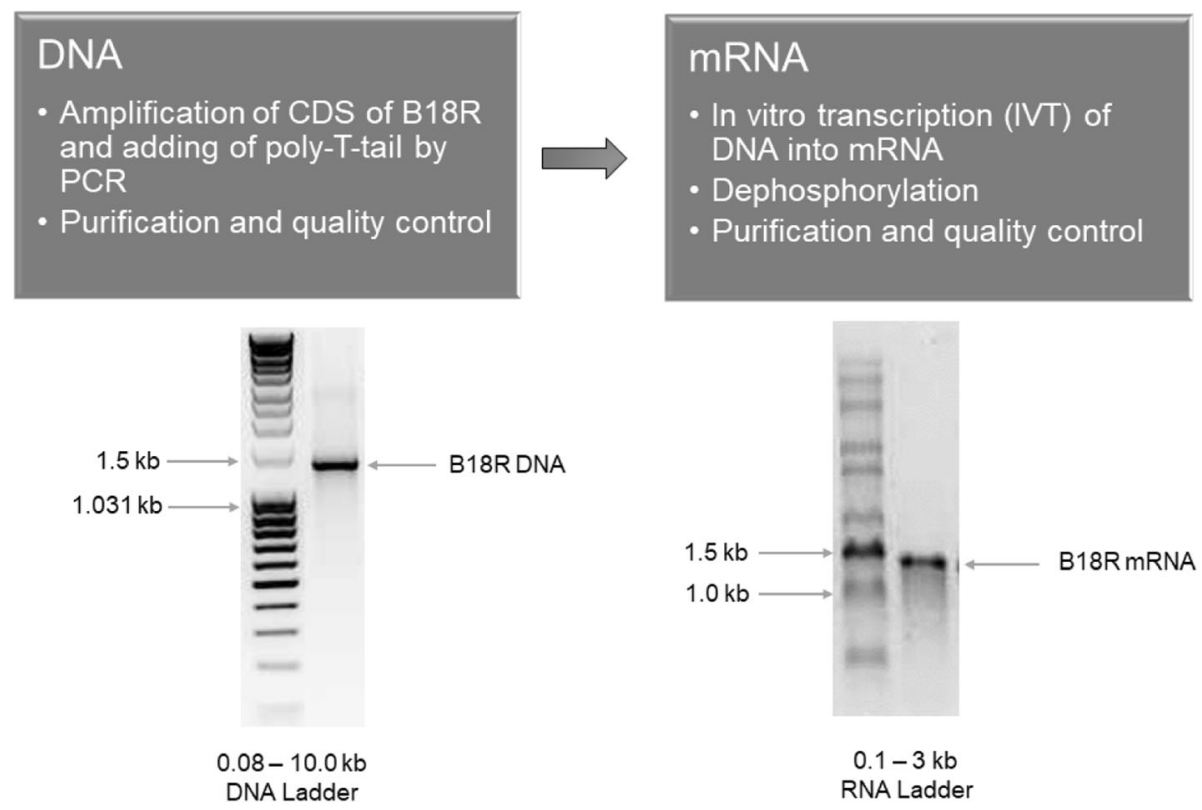

Fig. 2 Schematic representation of the modified B18R mRNA synthesis. The coding sequence (CDS) of B18R was amplified from the pcDNA 3.3 vector using PCR. The amplified DNA was purified and the quality was examined by the detection of a single DNA band of approximately 1400 bases. Afterwards, the amplified DNA was used as template for the in vitro transcription (IVT) to generate the B18R mRNA. After the IVT, the transcribed mRNA was dephosphorylated, purified, and the quality of mRNA was proved using $1 \%$ agarose gel electrophoresis and the detection of one clear band with about 1400 bases

resulted in a significantly higher eGFP expression compared to the cells transfected only with $1.5 \mu \mathrm{g}$ eGFP mRNA (Fig. 4b). The eGFP expression in cells transfected with $1.5 \mu \mathrm{g}$ eGFP mRNA and incubated with $200 \mathrm{ng} / \mathrm{ml}$ B18R protein was comparable to the eGFP expression in cells transfected with only $1.5 \mu \mathrm{g}$ eGFP mRNA. Furthermore, increasing the amount of B18R mRNA from 0.2 to $1.5 \mu \mathrm{g}$ did not result in significantly different eGFP expression.

Additionally to the flow cytometry analyses, the expression of eGFP was also detected by fluorescence microscopy (Fig. 5). In accordance with the flow cytometry experiments, especially $24 \mathrm{~h}$ after the second transfection, increased expression of eGFP could be seen compared to the cells transfected with only eGFP mRNA or cells transfected with eGFP mRNA and incubated with B18R protein.

Table 1 Detected B18R specific peptide sequences in the B18R mRNA transfected cell lysate

\begin{tabular}{lllll}
\hline Peptide Sequence & Proteins (UniProtKB) & PEP & Score & Intensity \\
\hline ILTVLPSQDHR & Q9DUN2 & $4.43 E-05$ & 109.16 & $16,468,000$ \\
EINIDDIK & Q9DUN2 & 0.019146 & 64.711 & $11,597,000$ \\
IKNDINSR & Q9DUN2 & 0.0013751 & 85.622 & $1,828,500$ \\
YLCTVITK & Q9DUN2 & 0.0070972 & 77.732 & $2,581,900$ \\
\hline
\end{tabular}

Abbreviation: PEP Posterior error probability

\section{Analysis of cell viability after the co-transfection of cells} with eGFP mRNA and B18R mRNA

In order to investigate the viability of eGFP mRNA transfected cells in comparison to the eGFP mRNA transfected cells treated with B18R protein or co-transfected with B18R mRNA, $1 \times 10^{5}$ fibroblasts were seeded per well of 6 -well plate and transfected daily up to 7 days with $1.5 \mu \mathrm{g}$ eGFP mRNA alone or with $1.5 \mu \mathrm{g}$ B18R mRNA. Additionally, cells were transfected with $1.5 \mu \mathrm{g}$ eGFP mRNA and incubated with $200 \mathrm{ng} / \mathrm{ml}$ B18R protein. Cells treated with Opti-MEM alone or Opti-MEM containing Lipofectamine 2000 served as controls. The cell viability was detected $24 \mathrm{~h}$ after each transfection using MTT assay (Fig. 6).

The repeated transfection of fibroblasts over 7 days resulted in a continuous significant decrease in cell viability. After 1 day, the cell viability of all treated cells was comparable. However, after the second transfection (Day 2), only eGFP mRNA transfected cells showed a significantly decreased cell viability. After 7 days of transfection, the cell viability of additionally B18R mRNA transfected $(65.26 \% \pm 20.64 \%)$ or B18R protein incubated $(76.82 \% \pm 10.42 \%)$ cells was significantly higher than the viability of only eGFP mRNA transfected cells $(17 \% \pm$ $5.52 \%)$. Furthermore, after 7 days, the viability of B18R mRNA co-transfected or B18R protein treated cells was not significantly different. A decrease of cell viability was detected until the 4th transfection, however, after the 


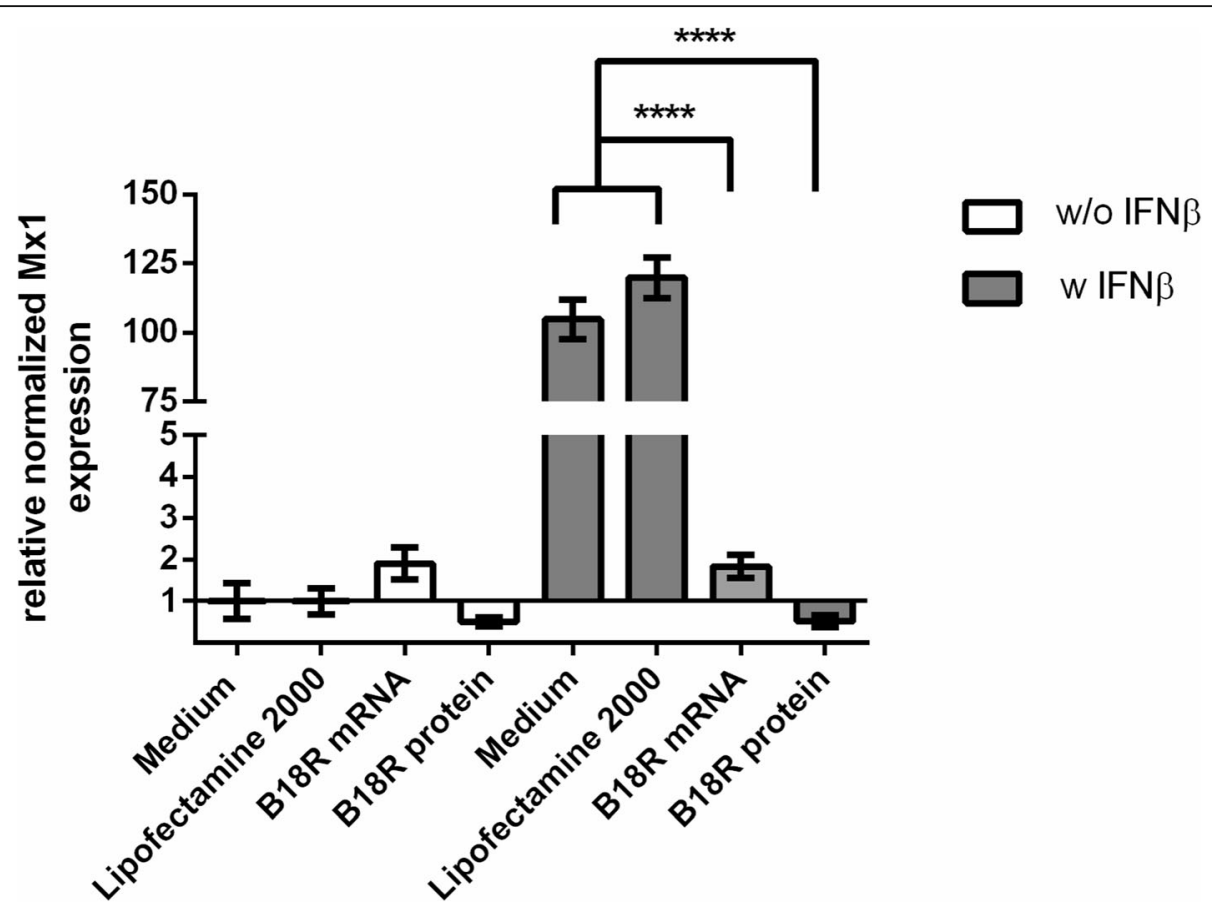

Fig. 3 qRT-PCR analysis of Mx1 expression in fibroblasts transfected with synthetic B18R mRNA or incubated with $200 \mathrm{ng} / \mathrm{ml}$ B18R protein and the following stimulation with IFN $\beta$. Fibroblasts were transfected with $1.5 \mu \mathrm{g}$ B18R mRNA or incubated with $200 \mathrm{ng} / \mathrm{ml}$ B $18 \mathrm{R}$ protein. After $24 \mathrm{~h}$, cells were stimulated for $3 \mathrm{~h}$ at $37^{\circ} \mathrm{C}$ and $5 \% \mathrm{CO}_{2}$ with $5 \mathrm{ng} / \mathrm{ml}$ IFNB. Subsequently, the $\mathrm{Mx} 1$ gene expression was analyzed using qRT-PCR. Results are presented as means \pm SEM $(n=3)$. Differences were analyzed using one-way ANOVA following Bonferroni's multiple comparison test. $\left({ }^{* * * *} p<0.0001\right)$
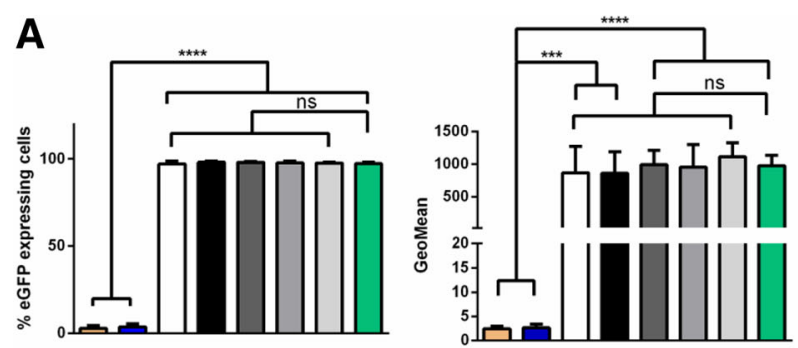

B
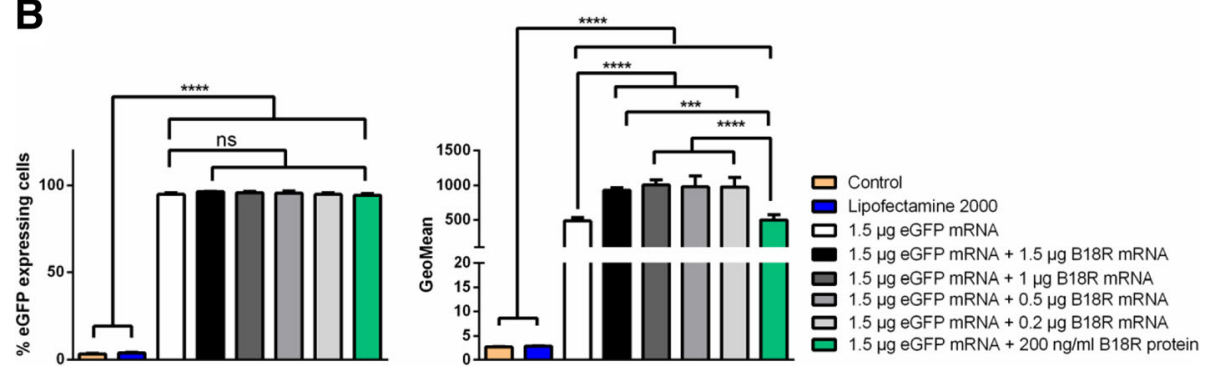

Fig. 4 Investigation of eGFP expression after the co-transfection of fibroblasts with eGFP mRNA and different amounts of B18R mRNA using flow cytometry. $1 \times 10^{5}$ fibroblasts were transfected for two following days with $1.5 \mu \mathrm{g}$ eGFP alone or with $0.2,0.5$, 1, or $1.5 \mu \mathrm{g}$ B18R mRNA. Cells treated with only Opti-MEM or Opti-MEM and the transfection reagent Lipofectamine 2000 served as negative controls. The eGFP expression was analyzed $24 \mathrm{~h}$ after (a) the first transfection and (b) the second transfection by flow cytometry. Results are presented as means \pm SD $(n=3)$. Differences were analyzed using one-way ANOVA following Bonferroni's multiple comparison test. $\left({ }^{* *} p<0.001,{ }^{* * * *} p<0.0001\right)$. ns: not significant 


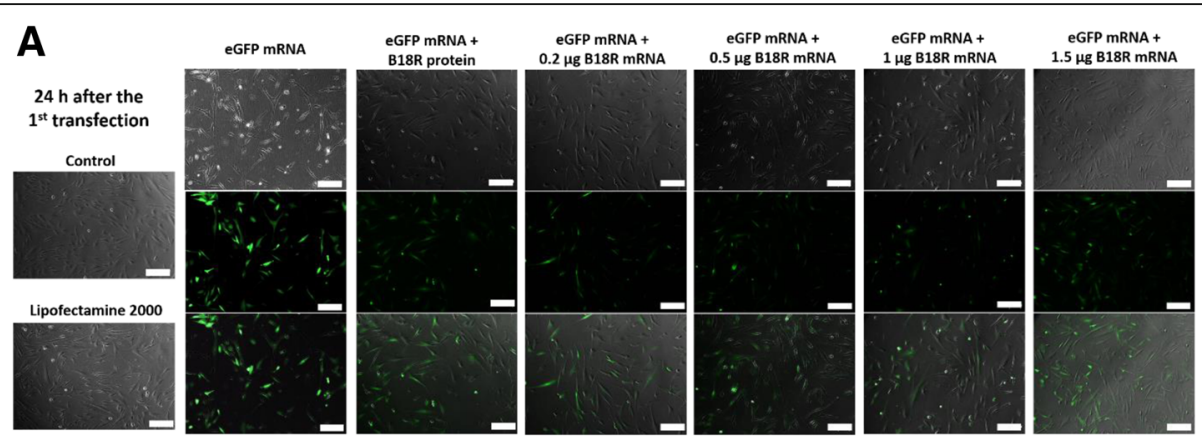

B

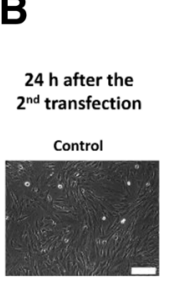
Lipofectamine 2000
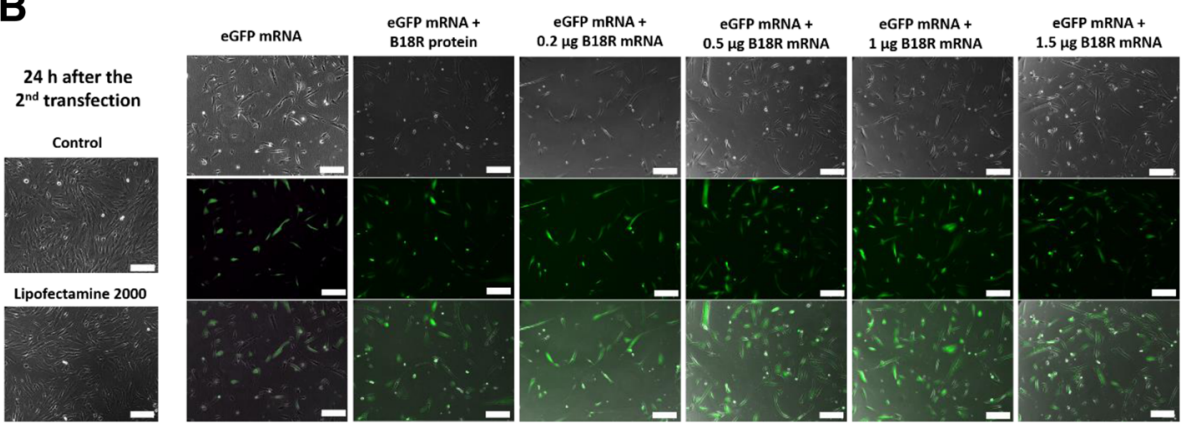

Fig. 5 Investigation of eGFP expression after the co-transfection of fibroblasts with eGFP mRNA and different amounts of B18R mRNA using fluorescence microscopy. $1 \times 10^{5}$ fibroblasts were transfected for two following days with $1.5 \mu \mathrm{g}$ eGFP mRNA alone or with $0.2,0.5,1$, or $1.5 \mu \mathrm{g}$ B18R mRNA. The eGFP expression was analyzed by fluorescence microscopy $24 \mathrm{~h}$ after (a) the first and (b) second transfection. Scale bar corresponds to $200 \mu \mathrm{m}$

5th transfection a continuous increase of cell viability was detected. After the 7th transfection, the cell viability was not significantly different than the detected levels after the 1st transfection.

\section{Discussion}

In recent years, synthetic mRNA is applied for therapy [43], vaccination [44], and regenerative medicine [45]. While the synthetic mRNA-mediated activation of immune system is desired in the field of vaccination, in other applications, the activation of the immune system due to the delivery of synthetic mRNA is undesired. However, the immune reaction of cells to synthetic RNA molecules is a natural defense mechanism to protect them against viral infections. Although single mRNA transfections seem to be accepted by cells, the repeated daily transfection of cells with synthetic mRNA or the use of self-replicating RNA for example for the generation of iPSCs requires the suppression of IFN response to be able to perform the reprogramming procedure $[37,38]$.

B18R protein is an immune suppressor that interrupts the IFN response by binding and neutralizing the type I IFNs [34]. In the present work, we generated synthetic B18R mRNA and detected the translated B18R protein after the delivery of B18R encoding mRNA into the cells using MS. The co-transfection of synthetic mRNA transfected cells with B18R mRNA resulted in comparable IFN response inhibiting properties as the treatment with recombinant B18R protein, which was demonstrated by the reduced gene expression levels of anti-viral protein $\mathrm{Mx} 1$.

After a single transfection of cells with eGFP mRNA, no significant differences in eGFP expression were obtained in cells co-transfected with B18R mRNA or incubated with recombinant B18R protein compared to the cells transfected with only eGFP mRNA. However, after the second eGFP mRNA transfection, the co-transfection of cells with B18R mRNA resulted in an improved eGFP protein expression in contrast to the cells treated with $B 18 R$ protein, which indicates that the B18R mRNA co-delivery has also a positive effect on translation of mRNA. This is possibly caused by reduced activation of the immune system and degradation of delivered synthetic mRNA.

After 7 consecutive eGFP mRNA transfections, significantly higher cell viability was detected in cells co-transfected with B18R mRNA or incubated with recombinant B18R protein compared to cells without B18R mRNA transfections or B18R protein treatment. In contrast, the repeated transfection of cells with only eGFP mRNA resulted in continuous decrease of cell viability. The cells treated with B18R mRNA demonstrated a similar cell viability as the cells treated with B18R 


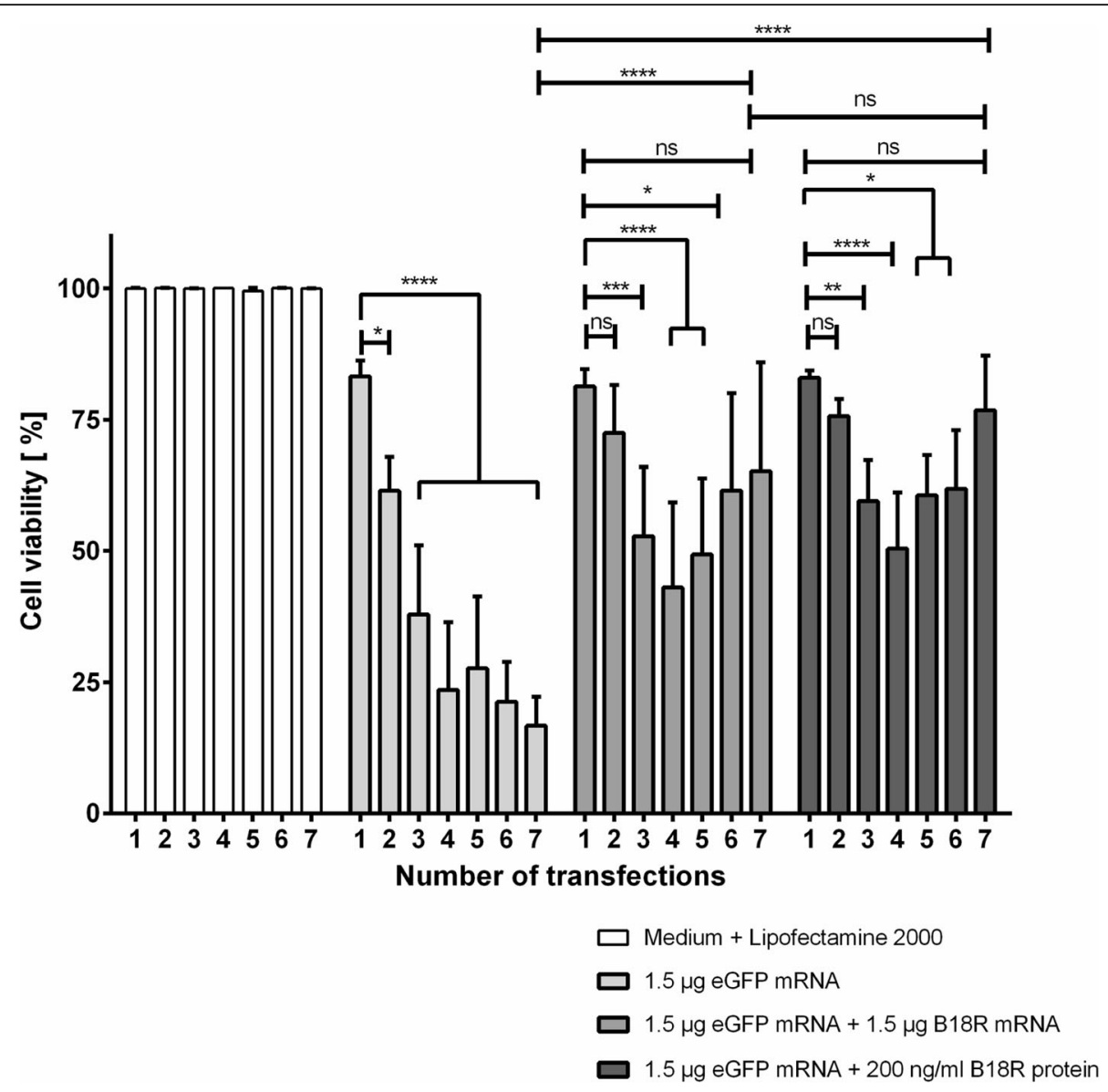

Fig. 6 Impact of co-transfection with synthetic B18R mRNA on cell viability. Fibroblasts were transfected daily up to 7 days with $1.5 \mu \mathrm{g}$ eGFP mRNA. Additionally, cells were transfected with $1.5 \mu \mathrm{g}$ eGFP mRNA and $1.5 \mu \mathrm{g}$ B18R mRNA or incubated with $200 \mathrm{ng} / \mathrm{ml}$ B18R protein after the transfection with $1.5 \mu \mathrm{g}$ eGFP mRNA. The viability of cells after the Lipofectamine 2000 treatment was set to $100 \%$. Results are presented as means $\pm \operatorname{SEM}(n=3)$. Differences were analyzed using two-way ANOVA following Bonferroni's multiple comparison test. $\left({ }^{*} p<0.05,{ }^{* *} p<0.01\right.$, $\left.{ }^{* * * *} p<0.0001\right)$. ns: not significant

protein. However, until 4th transfection, a continuous reduction of cell viability was detected also in B18R mRNA co-transfected cells and B18R protein treated cells. After the 5th transfection, a continuous increase in cell viability was measured. The reason therefore could be the required time for the blocking of all produced IFNs and the required time for the down-regulation of the expression of interferon-stimulated genes [46] and the adaptation of the cells. Possibly by starting B18R mRNA transfection or B18R protein treatment prior to the transfection with the desired mRNA, the protective effect could be reached immediately after the mRNA transfection of cells.

These results demonstrated that the cells transfected with synthetic mRNA could be simultaneously transfected with B18R encoding mRNA to reduce immune reactions and maintain the cell viability and protein expression. Thus, this method could be used for the long-term mRNA transfections and compared to the use of recombinant $\mathrm{B} 18 \mathrm{R}$ protein, the application of $\mathrm{B} 18 \mathrm{R}$ encoding mRNA is cheaper. Thereby, the transfected cells can produce their own IFN inhibiting protein. Particularly, in the field of iPSC generation using synthetic mRNAs, this method could be advantageous. Another possibility is also to transfect cells with B18R mRNA to obtain B18R conditioned medium, which can be used for the cultivation of mRNA transfected cells. Especially during the generation of iPSCs using self-replicating RNA, which requires only one transfection, the use of B18R conditioned medium could be beneficial.

\section{Conclusion}

In this study, we demonstrated that the simultaneous transfection of cells with B18R mRNA can suppress the synthetic mRNA induced IFN response in cells. Therefore, B18R encoding mRNA was generated and the cells were simultaneously transfected with eGFP mRNA and B18R mRNA. B18R mRNA treatment significantly 
improved the cell viability and the production of eGFP protein in eGFP mRNA transfected cells. In future, B18R mRNA could be used together with reprogramming mRNAs to reduce and simplify the reprogramming procedure. Using B18R mRNA delivery, the immune activation can be efficiently reduced especially in cells repeatedly transfected with synthetic mRNAs. Thus, the co-transfection of cells with B18R encoding mRNA can be used as an alternative to the incubation with recombinant B18R protein.

\section{Abbreviations}

ANOVA: Analysis of variance; ARCA: Anti-reverse cap analog; CDS: Coding sequence; DFG: German Research Foundation; DMSO: Dimethyl sulphoxide; FCS: Fetal calf serum; GAPDH: Glyceraldehyde 3-phosphate dehydrogenase; IFN: Interferon; IFNa: Interferon- $\alpha$; IFN $\beta$ : Interferon- $\beta$; iPSCs: induced pluripotent stem cells; ISGs: IFN-stimulated genes; IVT: In vitro transcription; LC: Liquid chromatography; m5C: 5-methylcytidine; mRNA: messenger RNA; MS: Mass spectrometry; MTT: 3-(4,5-dimethylthiazol-2-yl)-2,5-

diphenyltetrazoliumbromide; NF-kB: Nuclear factor KB; PCR: Polymerase chain reaction; PRRs: Pattern recognition receptors; qRT-PCR: Quantitative real-time polymerase chain reaction; RIG-I: Retinoic acid inducible gene I;

SEM: Standard error of the mean; STATS: Signal transductors and activators of transcription; TLRs: Toll-like receptors; $\Psi$ : Pseudouridine

\section{Acknowledgements}

Not applicable.

\section{Funding}

The authors would like to thank the German Research Foundation (DFG) for the financial support of this work under grant AV 133/7-1. Furthermore, we acknowledge support by Deutsche Forschungsgemeinschaft and Open Access Publishing Fund of University of Tuebingen.

\section{Availability of data and materials}

The datasets analyzed during the current study available from the corresponding author on reasonable request.

\section{Authors' contributions}

TM and SG contributed equally to the work. TM, SG, and MAA conceived and designed the experiments. TM and SG performed the experiments with the support from HS and LH. AV and BM performed and analyzed mass spectrometry experiments. MAA and HPW analyzed the data. HPW, SK, and CS contributed reagents/materials/analysis tools. TM, SG, and MAA wrote the paper. MAA supervised the project. All authors read and approved the final manuscript.

\section{Ethics approval and consent to participate}

Not applicable.

\section{Consent for publication}

Not applicable.

\section{Competing interests}

The authors declare that they have no competing interests.

\section{Publisher's Note}

Springer Nature remains neutral with regard to jurisdictional claims in published maps and institutional affiliations.

\section{Author details}

'Department of Thoracic and Cardiovascular Surgery, University Hospital Tübingen, Tübingen, Germany. ${ }^{2}$ Proteome Center Tübingen, Interfaculty Institute for Cell Biology, University of Tübingen, Tübingen, Germany.
Received: 31 January 2019 Accepted: 21 April 2019

Published online: 09 May 2019

\section{References}

1. Kubler H, Stenzl A, Schultze-Seemann W, Dorp FV, Pilla L, Hampel C, Jocham D, Development C, Miller K. Final analysis of a phase I/lla study with CV9103, an Intradermally administered prostate Cancer immunotherapy based on self Adjuvanted mRNA. Eur J Cancer. 2011;47:S498-9.

2. Fotin-Mleczek M, Duchardt KM, Lorenz C, Pfeiffer R, Ojkic-Zrna S, Probst J, Kallen KJ. Messenger RNA-based vaccines with dual activity induce balanced TLR-7 dependent adaptive immune responses and provide antitumor activity. J Immunother. 2011;34(1):1-15.

3. Petsch B, Schnee M, Vogel AB, Lange $E$, Hoffmann B, Voss D, Schlake $T$, Thess A, Kallen KJ, Stitz L, Kramps T. Protective efficacy of in vitro synthesized, specific mRNA vaccines against influenza a virus infection. Nat Biotechnol. 2012;30(12):1210-6.

4. Kormann MS, Hasenpusch G, Aneja MK, Nica G, Flemmer AW, Herber-Jonat S, Huppmann M, Mays LE, Illenyi M, Schams A, Griese M, Bittmann I, Handgretinger R, Hartl D, Rosenecker J, Rudolph C. Expression of therapeutic proteins after delivery of chemically modified mRNA in mice. Nat Biotechnol. 2011;29(2):154-7.

5. Tavernier G, Andries O, Demeester J, Sanders NN, De Smedt SC, Rejman J. mRNA as gene therapeutic: how to control protein expression. J Control Release. 2011;150(3):238-47.

6. Yamamoto A, Kormann M, Rosenecker J, Rudolph C. Current prospects for mRNA gene delivery. Eur J Pharm Biopharm. 2009;71(3):484-9.

7. Kariko K, Muramatsu H, Keller JM, Weissman D. Increased erythropoiesis in mice injected with submicrogram quantities of pseudouridine-containing mRNA encoding erythropoietin. Mol Ther. 2012;20(5):948-53.

8. Hacein-Bey-Abina S, Von Kalle C, Schmidt M, McCormack MP, Wulffraat N, Leboulch P, Lim A, Osborne CS, Pawliuk R, Morillon E, Sorensen R, Forster A, Fraser P, Cohen Jl, de Saint Basile G, Alexander I, Wintergerst U, Frebourg T, Aurias A, Stoppa-Lyonnet D, Romana S, Radford-Weiss I, Gross F, Valensi F, Delabesse E, Macintyre E, Sigaux F, Soulier J, Leiva LE, Wissler M, Prinz C, Rabbitts TH, Le Deist F, Fischer A, Cavazzana-Calvo M. LMO2-associated clonal T cell proliferation in two patients after gene therapy for SCID-X1. Science. 2003:302(5644):415-9.

9. Mays LE, Ammon-Treiber S, Mothes B, Alkhaled M, Rottenberger J, MullerHermelink ES, Grimm M, Mezger M, Beer-Hammer S, von Stebut E, Rieber N, Nurnberg B, Schwab M, Handgretinger R, Idzko M, Hartl D, Kormann MS. Modified Foxp3 mRNA protects against asthma through an IL-10dependent mechanism. J Clin Invest. 2013;123(3):1216-28.

10. Avci-Adali M, Behring A, Steinle H, Keller T, Krajeweski S, Schlensak C, Wendel HP. In vitro synthesis of modified mRNA for induction of protein expression in human cells. J Vis Exp (93). 2014:e51943.

11. Oh S, Kessler JA. Design, assembly, production, and transfection of synthetic modified mRNA. Methods. 2018;133:29-43.

12. Yamamoto A, Kormann M, Rosenecker J, Rudolph C. Current prospects for mRNA gene delivery, European journal of pharmaceutics and biopharmaceutics : official journal of Arbeitsgemeinschaft fur. Pharmazeutische Verfahrenstechnik eV. 2009;71(3):484-9.

13. Stepinski J, Waddell C, Stolarski R, Darzynkiewicz E, Rhoads RE. Synthesis and properties of mRNAs containing the novel "anti-reverse" cap analogs 7-methyl(3'-O-methyl)GpppG and 7-methyl (3'-deoxy)GpppG. Rna. 2001;7(10):1486-95.

14. Grudzien E, Kalek M, Jemielity J, Darzynkiewicz E, Rhoads RE. Differential inhibition of mRNA degradation pathways by novel cap analogs. J Biol Chem. 2006;281(4):1857-67.

15. Mockey M, Goncalves C, Dupuy FP, Lemoine FM, Pichon C, Midoux P. mRNA transfection of dendritic cells: synergistic effect of ARCA mRNA capping with poly(a) chains in cis and in trans for a high protein expression level. Biochem Biophys Res Commun. 2006;340(4):1062-8.

16. Kariko K, Muramatsu H, Welsh FA, Ludwig J, Kato H, Akira S, Weissman D. Incorporation of pseudouridine into mRNA yields superior nonimmunogenic vector with increased translational capacity and biological stability. Mol Ther. 2008;16(11):1833-40.

17. Anderson BR, Muramatsu H, Nallagatla SR, Bevilacqua PC, Sansing LH, Weissman D, Kariko K. Incorporation of pseudouridine into mRNA enhances translation by diminishing PKR activation. Nucleic Acids Res. 2010;38(17):5884-92 
18. Hausburg F, Na S, Voronina N, Skorska A, Muller P, Steinhoff G, David R. Defining optimized properties of modified mRNA to enhance virus- and DNA- independent protein expression in adult stem cells and fibroblasts. Cell Physiol Biochem. 2015;35(4):1360-71.

19. Kariko K, Buckstein M, Ni H, Weissman D. Suppression of RNA recognition by toll-like receptors: the impact of nucleoside modification and the evolutionary origin of RNA. Immunity. 2005;23(2):165-75.

20. Kariko K, Weissman D. Naturally occurring nucleoside modifications suppress the immunostimulatory activity of RNA: implication for therapeutic RNA development. Curr Opin Drug Discov Devel. 2007;10(5):523-32.

21. Heil F, Hemmi H, Hochrein H, Ampenberger F, Kirschning C, Akira S, Lipford $\mathrm{G}$, Wagner H, Bauer S. Species-specific recognition of single-stranded RNA via toll-like receptor 7 and 8. Science. 2004;303(5663):1526-9.

22. Alexopoulou L, Holt AC, Medzhitov R, Flavell RA. Recognition of doublestranded RNA and activation of NF-kappaB by toll-like receptor 3. Nature. 2001;413(6857):732-8.

23. Schmidt A, Schwerd T, Hamm W, Hellmuth JC, Cui S, Wenzel M, Hoffmann FS, Michallet MC, Besch R, Hopfner KP, Endres S, Rothenfusser S. 5'triphosphate RNA requires base-paired structures to activate antiviral signaling via RIG-I. Proc Natl Acad Sci U S A. 2009;106(29):12067-72.

24. Devoldere J, Dewitte H, De Smedt SC, Remaut K. Evading innate immunity in nonviral mRNA delivery: don't shoot the messenger. Drug Discov Today. 2016;21(1):11-25.

25. Kariko K, Ni H, Capodici J, Lamphier M, Weissman D. mRNA is an endogenous ligand for toll-like receptor 3. J Biol Chem. 2004;279(13):12542-50.

26. Kariko K, Bhuyan P, Capodici J, Weissman D. Small interfering RNAs mediate sequence-independent gene suppression and induce immune activation by signaling through toll-like receptor 3. J Immunol. 2004;172(11):6545-9.

27. Kariko K, Bhuyan P, Capodici J, Ni H, Lubinski J, Friedman H, Weissman D. Exogenous siRNA mediates sequence-independent gene suppression by signaling through toll-like receptor 3. Cells Tissues Organs. 2004;177(3):132-8.

28. Smith PL, Lombardi G, Foster GR. Type I interferons and the innate immune response--more than just antiviral cytokines. Mol Immunol. 2005;42(8):869-77.

29. Ivashkiv LB, Donlin LT. Regulation of type I interferon responses. Nat Rev Immunol. 2014;14(1):36-49

30. Rautsi O, Lehmusvaara S, Salonen T, Hakkinen K, Sillanpaa M, Hakkarainen T, Heikkinen S, Vahakangas E, Yla-Herttuala S, Hinkkanen A, Julkunen I, Wahlfors J, Pellinen R. Type I interferon response against viral and non-viral gene transfer in human tumor and primary cell lines. J Gene Med. 2007:9(2):122-35.

31. Haller O, Staeheli P, Schwemmle M, Kochs G. Mx GTPases: dynamin-like antiviral machines of innate immunity. Trends Microbiol. 2015;23(3):154-63.

32. Verhelst J, Parthoens E, Schepens B, Fiers W, Saelens X. Interferoninducible protein $M \times 1$ inhibits influenza virus by interfering with functional viral ribonucleoprotein complex assembly. J Virol. 2012;86(24):13445-55.

33. Colamonici OR, Domanski P, Sweitzer SM, Larner A, Buller RM. Vaccinia virus B18R gene encodes a type I interferon-binding protein that blocks interferon alpha transmembrane signaling. J Biol Chem. 1995;270(27):15974-8.

34. Alcami A, Symons JA, Smith GL. The vaccinia virus soluble alpha/beta interferon (IFN) receptor binds to the cell surface and protects cells from the antiviral effects of IFN. J Virol. 2000;74(23):11230-9.

35. Angel M, Yanik MF. Innate immune suppression enables frequent transfection with RNA encoding reprogramming proteins. PLOS One. 2010;5(7):e11756.

36. Drews K, Tavernier G, Demeester J, Lehrach H, De Smedt SC, Rejman J, Adjaye J. The cytotoxic and immunogenic hurdles associated with non-viral mRNA-mediated reprogramming of human fibroblasts. Biomaterials. 2012;33(16):4059-68

37. Warren L, Manos PD, Ahfeldt T, Loh YH, Li H, Lau F, Ebina W, Mandal PK, Smith ZD, Meissner A, Daley GQ, Brack AS, Collins JJ, Cowan C, Schlaeger TM, Rossi DJ. Highly efficient reprogramming to pluripotency and directed differentiation of human cells with synthetic modified mRNA. Cell Stem Cell. 2010;7(5):618-30.

38. Yoshioka N, Gros E, Li HR, Kumar S, Deacon DC, Maron C, Muotri AR, Chi NC, Fu XD, Yu BD, Dowdy SF. Efficient generation of human iPSCs by a synthetic self-replicative RNA. Cell Stem Cell. 2013;13(2):246-54.

39. Mandal PK, Rossi DJ. Reprogramming human fibroblasts to pluripotency using modified mRNA. Nat Protoc. 2013;8(3):568.

40. Burian M, Velic A, Matic K, Gunther S, Kraft B, Gonser L, Forchhammer S, Tiffert Y, Naumer C, Krohn M, Berneburg M, Yazdi AS, Macek B, Schittek B.
Quantitative proteomics of the human skin secretome reveal a reduction in immune defense mediators in ectodermal dysplasia patients. J Invest Dermatol. 2015;135(3):759-67.

41. Cox J, Mann M. MaxQuant enables high peptide identification rates, individualized p.p.b.-range mass accuracies and proteome-wide protein quantification. Nat Biotechnol. 2008;26(12):1367-72.

42. Olsen JV, de Godoy LM, Li G, Macek B, Mortensen P, Pesch R, Makarov A, Lange $\mathrm{O}$, Horning S, Mann M. Parts per million mass accuracy on an Orbitrap mass spectrometer via lock mass injection into a C-trap. Mol Cell Proteomics. 2005;4(12):2010-21.

43. Ramaswamy S, Tonnu N, Tachikawa K, Limphong P, Vega JB, Karmali PP, Chivukula P, Verma IM. Systemic delivery of factor IX messenger RNA for protein replacement therapy. Proc Natl Acad Sci. 2017:201619653.

44. Vogel AB, Lambert L, Kinnear E, Busse D, Erbar S, Reuter KC, Wicke L, Perkovic M, Beissert T, Haas H. Self-amplifying RNA vaccines give equivalent protection against influenza to mRNA vaccines but at much lower doses. Mol Ther. 2018;26(2):446-55.

45. Kwon H, Kim M, Seo Y, Moon YS, Lee HJ, Lee K, Lee H. Emergence of synthetic mRNA: in vitro synthesis of mRNA and its applications in regenerative medicine. Biomaterials. 2017.

46. Haller O, Kochs $\mathrm{G}$, Weber F. The interferon response circuit: induction and suppression by pathogenic viruses. Virology. 2006:344(1):119-30.

\section{Ready to submit your research? Choose BMC and benefit from:}

- fast, convenient online submission

- thorough peer review by experienced researchers in your field

- rapid publication on acceptance

- support for research data, including large and complex data types

- gold Open Access which fosters wider collaboration and increased citations

- maximum visibility for your research: over $100 \mathrm{M}$ website views per year

At $\mathrm{BMC}$, research is always in progress.

Learn more biomedcentral.com/submissions 